\title{
Peritoneal progression after pancreaticoduodenectomy is a devastating surgical treatment failure: HIPEC gemcitabine is an option
}

\author{
Paul H. Sugarbaker ${ }^{1}$, Kurt Van der Speeten ${ }^{2}$ \\ ${ }^{1}$ MedStar Washington Hospital Center, Washington, DC, USA; ${ }^{2}$ Department of Surgery, Hospital Oost-Limburg, Genk, Belgium \\ Correspondence to: Paul H. Sugarbaker, MD. MedStar Washington Hospital Center, Washington, DC, USA. Email: Paul.Sugarbaker@outlook.com; \\ Kurt Van der Speeten. Department of Surgery, Hospital Oost-Limburg, Genk, Belgium. Email: Kurt.Vanderspeeten@zol.be. \\ Comment on: Padilla-Valverde D, García-Santos E, Sanchez S, et al. Safety of perioperative hyperthermic intraperitoneal chemotherapy with \\ gemcitabine in patients with resected pancreatic adenocarcinoma: a pilot study of the clinical trial EudraCT 2016-004298-41. J Gastrointest Oncol \\ 2021;12:S80-90. \\ Tentes AAK. Hyperthermic intra-operative intraperitoneal chemotherapy as an adjuvant to pancreatic cancer resection. J Gastrointest Oncol \\ 2021;12:S91-8. \\ Sugarbaker PH, Stuart OA. Intraperitoneal gemcitabine chemotherapy is safe for patients with resected pancreatic cancer: final clinical and \\ pharmacologic data from a phase II protocol and recommended future directions. J Gastrointest Oncol 2021;12:S99-109. \\ Yamada S, Fujii T, Yamamoto T, et al. Conversion surgery in patients with pancreatic cancer and peritoneal metastasis. J Gastrointest Oncol \\ 2021;12:S110-7.
}

Submitted Dec 16, 2020. Accepted for publication Mar 16, 2021.

doi: 10.21037/jgo-2020-14

View this article at: http://dx.doi.org/10.21037/jgo-2020-14

Perhaps it is a surprise to our readers of this Focused Issue that 4 manuscripts concerning PM from pancreas cancer are included (1-4). However, peritoneal recurrence is a devastating part of the natural history of this disease. David Padilla-Valverde and colleagues from Ciudad Real, Tentes from Athens, and Sugarbaker and Stuart from Washington, DC all focus on HIPEC with gemcitabine to help control local recurrence and PM in patients with resected pancreas cancer. The high incidence of early localregional progression following pancreas cancer resection causes extensive morbidity and interferes with possible benefits of systemic chemotherapy. The Spanish group presents their clinical trial data showing no unexpected morbidity and mortality if HIPEC gemcitabine is added to a pancreatico-duodenal resection (1). Tentes and Sugarbaker present similar safety data regarding HIPEC gemcitabine $(2,3)$. Mature but non-randomized data regarding reduced local-regional treatment failures were presented by Tentes $(10.3 \%)$ and by Sugarbaker (0\%). Sugarbaker and Stuart presented pharmacokinetic data strongly supporting HIPEC gemcitabine as a treatment to suppress the high likelihood of local-regional treatment failure in resected pancreas cancer. Also, 6 months of NIPEC gemcitabine through an intraperitoneal port was well tolerated. These authors suggest HIPEC and NIPEC gemcitabine can be included in multimodality strategies to treat resected pancreas cancer. Yamada and coworkers provide this Focused Issue data on a multi-institutional study from 10 different Japanese universities (4). In two different protocols of 33 and 46 patients, combined intraperitoneal paclitaxel and systemic chemotherapy were administered until unacceptable toxicity, disease progression or conversion surgery that occurred in 16 of the 79 patients $(20.3 \%)$. The "super responders" who had the benefit of conversion surgery showed an overall survival of 32.5 months. These authors concluded that repeated doses of combined intraperitoneal paclitaxel and systemic chemotherapy showed efficacy and was tolerable.

\section{Acknowledgments}

Funding: None. 


\section{Footnote}

Provenance and Peer Review: This article was commissioned by the editorial office, Fournal of Gastrointestinal Oncology for the focused issue "Intraperitoneal Chemotherapy for Peritoneal Metastases: HIPEC, EPIC, NIPEC, PIPAC and More". The article did not undergo external peer review.

Conflicts of Interest: Both authors have completed the ICMJE uniform disclosure form (available at http:// dx.doi.org/10.21037/jgo-2020-14). The focused issue was sponsored by the Peritoneal Surface Oncology Group International (PSOGI). Drs. PHS and KVDS served as the unpaid Guest Editors of the focused issue. The authors have no other conflicts of interest to declare.

Ethical Statement: The authors are accountable for all aspects of the work in ensuring that questions related to the accuracy or integrity of any part of the work are appropriately investigated and resolved.

Open Access Statement: This is an Open Access article distributed in accordance with the Creative Commons Attribution-NonCommercial-NoDerivs 4.0 International License (CC BY-NC-ND 4.0), which permits the non-

Cite this article as: Sugarbaker PH, Van der Speeten K. Peritoneal progression after pancreaticoduodenectomy is a devastating surgical treatment failure: HIPEC gemcitabine is an option. J Gastrointest Oncol 2021;12(Suppl 1):S118-S119. doi: 10.21037/jgo-2020-14 commercial replication and distribution of the article with the strict proviso that no changes or edits are made and the original work is properly cited (including links to both the formal publication through the relevant DOI and the license). See: https://creativecommons.org/licenses/by-nc-nd/4.0/.

\section{References}

1. Padilla-Valverde D, García-Santos E, Sanchez S, et al. Safety of perioperative hyperthermic intraperitoneal chemotherapy with gemcitabine in patients with resected pancreatic adenocarcinoma: a pilot study of the clinical trial EudraCT 2016-004298-41. J Gastrointest Oncol 2021;12:S80-90.

2. Tentes AAK. Hyperthermic intra-operative intraperitoneal chemotherapy as an adjuvant to pancreatic cancer resection. J Gastrointest Oncol 2021;12:S91-8.

3. Sugarbaker PH, Stuart OA. Intraperitoneal gemcitabine chemotherapy is safe for patients with resected pancreatic cancer: final clinical and pharmacologic data from a phase II protocol and recommended future directions. J Gastrointest Oncol 2021;12:S99-109.

4. Yamada S, Fujii T, Yamamoto T, et al. Conversion surgery in patients with pancreatic cancer and peritoneal metastasis. J Gastrointest Oncol 2021;12:S110-7. 